\title{
Affordability of household water and wastewater charges in Manukau City: a case study
}

\author{
B. Mahmood \& S. Sharma \\ Department of Civil Engineering, Unitec New Zealand, New Zealand
}

\begin{abstract}
Low-income households spend a substantial share of their income on utility services such as electricity, heating and water. The difficulty of these socially vulnerable consumers to absorb further price increases is often used as an argument against increasing rates. However, detailed quantitative information on the affordability of rate adjustments for low-income consumers is actually quite scarce. Much of the available information is based on total household's expenses. This study takes a more detailed look at the affordability of water and wastewater service's charges for low-income consumers in Manukau City. While there was no sufficient available data, the project finds that affordability is a problem for low-income consumers in Manukau. Given all household groups of income categories the percentage income spent on water and wastewater was determined and compared with an acceptable benchmark. It was found that the average amount spent on water and wastewater has increased at a higher rate (i.e. $26.84 \%$ ) than the average income (i.e. 3.15\%) in all income groups, and the burden of water and wastewater rates is increasing in terms of percentage of weekly income spent on it, especially, in the lower income earners category. The low-income earners spent $3.24 \%$ of their weekly income on water and wastewater service charges in 2001 and were spending $4.11 \%$ in 2006 . The proportion of household spending more than $3 \%$ of their income on water and sewerage charge was $14.6 \%$ in 2001 and $13.3 \%$ in 2007 , and proportion of household falling into this category has declined by $1.3 \%$ since 2001 . The results showed that a higher number of households may have faced a financial hardship, since 2001. In order to make the government and water industries aware of this problem, the term "affordability" needs to be taken into account as an assistant of the assessment of household water and sewerage services in Manukau City or wider over New Zealand.
\end{abstract}

Keywords: affordability, water and wastewater services charges. 


\section{Defining and measuring affordability}

Although now widely used of political and media commentators, the term 'affordability' has come to enjoy this degree of prominence in the context of the water industry in many OECD countries, only within the last decade. The reasons for this are the beyond the scope of this paper. Huby [9] and Herbert and Kempson [8] employed the terms "water poverty" and "water affordability" in analyzing links between these phenomena and household incomes. As yet, full consensus has not emerged over whether the word "poverty" or "affordability" is most appropriate when discussing the issue in the context of the water industry. Authors such as Huby [9] and Fitch [7] have favoured the former: the Organization for Economic Co-operation and Development (OECD) [12]; Watervoice [14] and Scotland's Water Customer Consultation Panels favored the latter. Although the terminology remains disputed, the fact that households will not be physically deprived of water services in the case of non-payment (as the disconnection of household water in no longer permitted in England - DEFRA, 2004). Therefore, the term "affordability" is more favored chosen in the category of water supply. That is the reason why OECD [12], in seeking to measure and calibrate, interprets "affordability" as "ability to pay". Superficially this definition is clear-cut. Practically, the difficulties in measuring the phenomenon are considerable.

However, affordability is the social aspect of water service provision that is most clearly and closely linked to pricing policies. Affordability of water service may not be distributed equally across income groups or neighbourhoods - a lower income household will inevitably pay a higher proportion of their income for water services than a higher income household does [12]. In fact, one thing needs to be noticed is that there is no equivalent standard as fuel poverty (i.e. a fuel poor household is the one which needs to spend more than $10 \%$ of its income on all fuel uses and to heat its home to an adequate standard of warmth) has been set for water [13], although an indicative affordability benchmark for water rates has been reported by many governments and international organization, for example, 3-5\% by World Bank, 3\% by UK government, and $2.5 \%$ by US government [6].

Sawkins and Dickie [13] reported that there are two classification concepts for water affordability measurement. One is focusing on aggregate, called macro affordability measures, and the other is disaggregated or micro affordability measure. Macro measures relate average household water charges to either average household income or average household expenditure for whole countries. Its main flaws lie in the failure to convey any significant information about the situation of low income households, it is not with regard to regional, company or municipal variation, and its conflating of essential and luxury water use. It is sometimes not good to be used to approach to the analysis of low income households because this measurement is not taking account of any specific variation. Whereas, micro affordability measures on the other hand allow disaggregating in various ways: by income group, by region, by family type or by a particular burden threshold. It concerns the situation from low 
income to high income families, and it just fills the part that might be missed while taking the macro measures.

The main reason lie behind the importance of affordability issues is the recent large and sustained rise in the average water and sewerage charges of Manukau city households, which need to develop its water and sewerage pricing system. However, the higher investing causes the higher rate of increasing water and sewerage service price. Therefore, adequacy of adjusting the household water and sewerage services prices is very important to get the balance of the water industry performance and the public benefit. This paper seeks to shed some light on the under-researched topic of water and wastewater affordability, briefly discusses the meaning of affordability and how it can be measured, and analyses the issue of water and sewage service charges affordability in the city. The aim of this study was to assess and analyse the issue of affordability for household water and wastewater charges in Manukau City. The specific objectives of this study were to determine and compare (i) the water consumption trends per household (from low to high income groups) over the past 7 years, (ii) the water and wastewater service charges over the past 7 years, and (iii) the percentage of income spent (from low to high income groups) on water and wastewater services charges in the study area.

\section{Methodology}

\subsection{Manukau city overview}

Manukau is situated in the Auckland Region. Manukau city is the fastest growing city in the region. Most of the water supplied around the city is controlled by Manukau Water Limited. The 15\% percent of the population that are not supplied with water by Manukau Water Limited are in rural areas. The urban population of Manukau City is expected to increase by $33 \%$ over the next 20 -year period from 319000 to 425000 people in 2027. The business sector's average annual growth rate of $5.5 \%$ per annum is expected to continue with significant growth around the Auckland International Airport and at the Highbrook development in East Tamaki. Even with water demand management initiatives aimed at reducing the per capita demand, the demand for water is forecasted to increase from $37 \mathrm{Mm}^{3} /$ year to $50 \mathrm{Mm}^{3} /$ year by 2027 [11]. Table 1 below provides an overview of the water services provided to the residents of Manukau city (during 2005 and 2006).

\subsection{Data collection and analysis}

The data relevant to population and gross income per income group (from low to high income) was obtained from Statistics of New Zealand for the 1996, 2001 and 2006 census. The number of people per household was also obtained from Statistics of New Zealand for 2001 and 2006 (as no data was available for 1996).

The data relevant to number of households connected with meters, water and wastewater charges, water consumption/demand was obtained from Manukau 
City Council (MCC) for the period from 2001-2007. The water consumption $(1 / \mathrm{h} /$ day) was estimated by dividing the city annual domestic water consumption (converted to daily basis) with the population connected to meters for each year (i.e. from 2001 to 2007). The water consumption per household was estimated multiplying the estimated water consumption $(1 / \mathrm{h} /$ day) with the average number of people per household (i.e. 3.35).

Table 1: An overview of water services provided to the residents of Manukau city (Sources: Auckland Water Industry Annual Performance Review, 2005/06 [1]).

\begin{tabular}{|l|l|}
\hline Population served & 325510 \\
\hline Total properties served & 97404 \\
\hline Residential properties served & $91604(94 \%)$ \\
\hline Non-residential properties served & $5800(6 \%)$ \\
\hline Total water serviced area (ha) & 14541 \\
\hline Water serviced area within MUL (Metropolitan Urban limits - ha) & Almost 100\% \\
\hline Bulk water supplied to customers (m ${ }^{3}$ /annually) & $36,546,989$ \\
\hline Length of water mains (km) & 1962 \\
\hline Water meters (no.) & 96626 \\
\hline Water pumping stations (no.) & 4 \\
\hline
\end{tabular}

The water charges per household (on daily and weekly basis) were determined for each year (i.e. from 2001 to 2007) using water unit price $\left(\left(\$ / \mathrm{m}^{3}\right)\right.$ and water consumption per household data. A fixed annual charge of \$50 for the usage of water meter in the city was added to the estimated annual water charges for each year. In this study, the issue of affordability is analysed in a way that water and sewerage service are banding together, because it can give a direct assessment of affordability of the residents of the city to pay the water and wastewater service's charges. Therefore, the annual water \& wastewater charges and fixed meter charges were added to get the total annual water and wastewater service charges. The annual values were converted to weekly values.

In a study similar to this one [10] which was undertaken for Waitakere City Council of New Zealand, a 3\% value was also assumed as a benchmark to analyse an affordability benchmark for household water and wastewater charges for the Waitakere city of New Zealand. The details of which can be found in [10]. Therefore, a $\mathbf{3 \%}$ value was also assumed (in this study) as a benchmark to assess and analyse an affordability benchmark for household water and sewerage charges in the Manukau city. Scotland used a 3\% water affordability benchmark and that was the other reason to choose this value, as the financial condition and residential situation are more similar between New Zealand and Scotland, than other countries.

In the same study [10] it was assumed that the amount of water consumption is same $(680 \mathrm{l} / \mathrm{h} / \mathrm{d})$ per household for each year. In this study we were able to estimate the water consumption or demand per household for each year, which 
makes this study more precise and accurate. However, there were few problems to contend with in drawing general conclusions about household water and sewerage affordability issues. For example, the data that is available for the purposes of analysis was not detailed and lacks in household composition, especially for the lowest to medium income households. Further, there is wide variation in individual circumstances. Having acknowledged these problems it was, nevertheless, possible to draw together the data in a way that enables a preliminary analysis of particular circumstances, and from there to draw some conclusions. The proportion of gross income spent on water and wastewater charges in Manukau were determined (form lowest to highest income group).

\section{Results and discussions}

\subsection{Population and household growth}

The population of Manukau city has increased by $15 \%$ (i.e. from 285450 to 328511 ) over the past 7 years (from 2000 to 2007 - 100\% connected with meters). It is estimated that the population of Manukau city may increase up to 560,000 by 2051 (almost $96 \%$ increase from 2000/01). Since 2001 the number of households has increased by $18.1 \%$ (i.e. from 53088 in 2001 to 62702 in 2006). The results showed that the average number of people per household in Manukau also increased from 3.3 people per household in 2001 to 3.4 people per household in 2006/07.

\subsection{Income distribution in Manukau city}

The results showed that there were 8091 families whose annual income was below \$20000, and 7380 families earned between $\$ 20001$ and $\$ 30000$ in 2001 . The majority of families in Manukau earned between $\$ 30000$ and $\$ 50000$ totaling a number of 11001 families in 2001. Families earning more than $\$ 50000$ also had significantly high numbers (i.e. 10884 in 2001 - Table 2). The number of families earning less than $\$ 20,000$ increased from 8091 families in 2001 to 9639 in 2006 (i.e. an increase of 19\%), as shown in Table 2. There was an increase of $18.1 \%$ in total number of households i.e. from 53088 in 2001 to 62702 in 2006 . On average, the proportion of household spending (in 1 and 2 low income groups) more than $3 \%$ of their gross income on water and wastewater services was $14.6 \%$ in 2001 and $13.3 \%$ in 2007 (on average a fall of $1.3 \%$ ). The results showed that the mean weekly income of the lowest income group increased by $3.15 \%$ during 2001 and 2006 (i.e. from $\$ 317$ to $\$ 327$ ).

\subsection{Water consumption}

The results showed that the water consumption or demand of a person per day increased by $6.14 \%$ (from 179 to $190 \mathrm{l} / \mathrm{h}$ /day) over the period of 7 years (i.e. from $2000 / 01$ to $2006 / 7$ ). Even though there have been minor fluctuations of around 2 litres against the upward trend. The largest plunge of 9 litres came in 
Table 2: $\quad$ The number of households and proportion of household within each income group for 2001 and 2006.

\begin{tabular}{|c|c|c|c|c|c|c|}
\hline Year & $\begin{array}{l}\text { Income } \\
\text { group }\end{array}$ & $\begin{array}{l}\text { Mean } \\
\text { weekly } \\
\text { gross } \\
\text { income } \\
(\$)\end{array}$ & $\begin{array}{l}\text { Number of } \\
\text { household }\end{array}$ & $\begin{array}{l}\text { Mean gross } \\
\text { weekly } \\
\text { household } \\
\text { income } \\
\text { spent on } \\
\text { water \& } \\
\text { sewerage } \\
\text { (\%age) }\end{array}$ & $\begin{array}{l}\text { Total } \\
\text { number of } \\
\text { households }\end{array}$ & $\begin{array}{l}\text { Proportion } \\
\text { of } \\
\text { household } \\
\text { in each } \\
\text { income } \\
\text { group (\%) }\end{array}$ \\
\hline \multirow[t]{6}{*}{2001} & $\begin{array}{l}1 \\
\text { Lowest }\end{array}$ & 317 & 8091 & 3.24 & 53088 & 15.24 \\
\hline & 2 & 330 & 7380 & 3.12 & & 13.90 \\
\hline & 3 & 381 & 11001 & 2.70 & & 20.72 \\
\hline & 4 & 577 & 10884 & 1.78 & & 20.50 \\
\hline & 5 & 962 & 8514 & 1.07 & & 16.04 \\
\hline & $\begin{array}{l}6 \\
\text { Highest }\end{array}$ & 1923 & 7218 & 0.54 & & 13.60 \\
\hline \multirow[t]{6}{*}{2006} & $\begin{array}{l}1 \\
\text { Lowest }\end{array}$ & 327 & 9639 & 3.98 & 62702 & 15.37 \\
\hline & 2 & 340 & 7005 & 3.83 & & 11.17 \\
\hline & 3 & 392 & 12654 & 3.32 & & 20.18 \\
\hline & 4 & 587 & 11445 & 2.22 & & 18.25 \\
\hline & 5 & 981 & 13326 & 1.33 & & 21.25 \\
\hline & $\begin{array}{l}6 \\
\text { Highest }\end{array}$ & 1935 & 8633 & 0.67 & & 13.77 \\
\hline
\end{tabular}

between the years 2003 and 2004. This increase was due to the increase in population and therefore an increase in water supply demand of the city.

The study showed that there was no significant difference in the water consumption between low and medium income households for each year. The highest income group was consuming 13\% extra water than the lowest to medium income groups. This difference only appeared in the water charges, and the sewerage charges do not vary. The mean weekly water and sewerage charges were slightly higher for the 2 highest income groups, which was basically due to the $13 \%$ extra luxury use of water by those income groups (Figure 1). The results also showed that the greatest demand per year was from the domestic user category (i.e. 61\%) in Manukau; therefore it is safe to say that the bulk of the water rates in Manukau are paid by the domestic sector, hence being the major income source for Manukau Water Limited.

\subsection{Water and wastewater charges}

The water unit price $\left(\$\right.$ per $\mathrm{m}^{3}$ ) increased from $\$ 1.12$ in 2000 to $\$ 1.20$ in 2007 (i.e. an increase of $7.14 \%$ ). Greater demand and stronger legislations are seemingly the main reasons for this increase, whereby greater infrastructure has to be installed and maintained. The wastewater charges increased from \$290.5 in 2001 to $\$ 350$ in 2007 (i.e. an increase of $20.5 \%$ over 7 years). Whereas, the total 
water and wastewater charges (combined including the fixed cost of meter) increased from $\$ 535.15$ in 2001 to $\$ 678.8$ in 2007 i.e. an increase of $26.84 \%$ (i.e. on average $4.47 \%$ per year). The household water bills have risen substantially, but unevenly since 2000 . This increase can be attributed to an accelerate increase of population, urbanisation of the City (over the last seven years), and water quality and increasing stringent environmental standards.

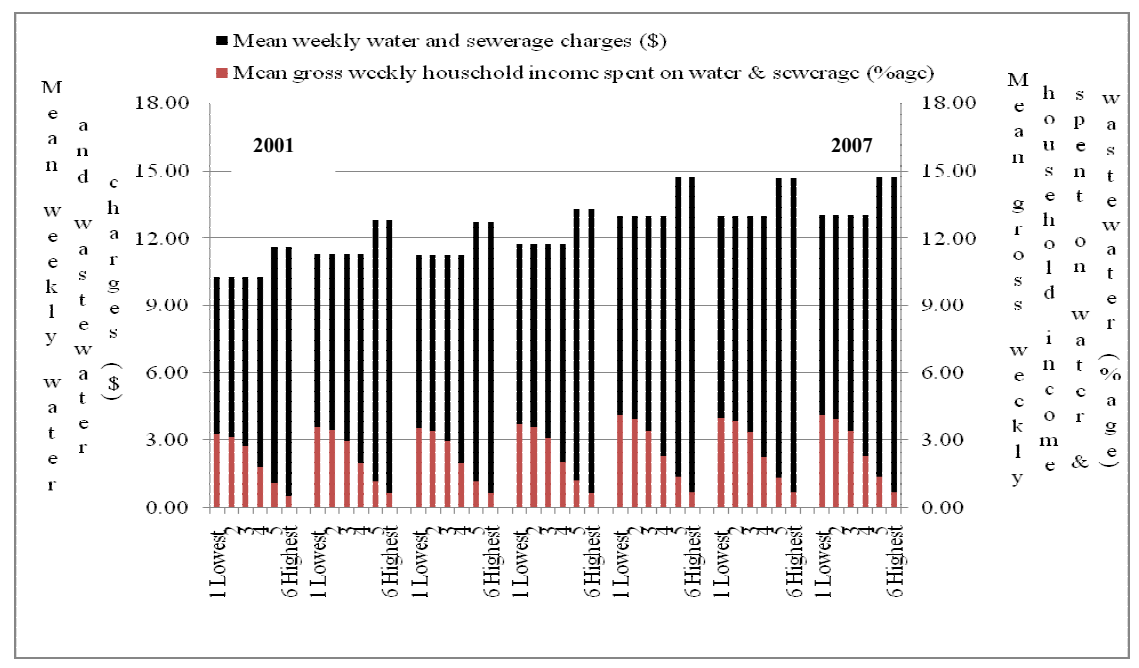

Figure 1: A comparison of mean weekly water and wastewater charges and the percentage of weekly gross income spent by each income group on water and sewerage services from 2001 to 2007.

The results showed that the percentage of income spent on water and wastewater service charges from highest to lowest income group varies between $0.54 \%$ and $3.24 \%$ in 2001 . Whereas for 2007, the percentage of income spent on water and wastewater service's charges varies between $0.68 \%$ and $4.11 \%$ (from highest to lowest income group - Figure 1). The results also showed that the percentage of income spent by lowest income group on water and wastewater charges increased by $\mathbf{2 6 . 8 5 \%}$ during 2001 and 2007 (i.e. from 3.24 to $4.11 \%$ ). The percentage of income spent by highest income group on water and wastewater charges increased by $25.92 \%$ (i.e. from 0.54 to $0.68 \%$ over the studied period - Figure 1). This showed that there was no significant difference in the rate of increase of income spent on water and wastewater charges between the lowest and highest income groups. However, the lowest income groups were spending a big slice of their income on water and sewerage charges than that of highest income group.

The results showed that the lowest income household group paid $3.24 \%$ of their income into water and sewerage service weekly in 2001, which was more than the assumed benchmark of $3 \%$. While in 2007 , it increased to $4.11 \%$ (i.e. an excess of $1.11 \%$ over the assumed benchmark of $3 \%$ ). This means that water and 
sewerage service charges have been unaffordable for the lowest income group since 2001. This group was taking $15.37 \%$ of Manukau city households (Table 2). When the weekly income data was compared to the weekly amount spent on water and wastewater (Figure 1) it was observed that lower income earners (i.e. income group 1 and 2) fail to meet the assumed benchmark. In 2001 families earning $\$ 350$ a week or more did not struggle to meet the benchmark and only the 2 lower income group failed to meet the 3\% benchmark. In 2006, the income groups 1,2 and 3 fail to meet the 3\% benchmark. Comparatively, in 2006 households earning over $\$ 420$ per week met the benchmark of 3\% (i.e. income groups of 4, 5 and 6).

As mentioned earlier that since 2001 the drinking water and wastewater charges increased by $7.14 \%$ and $20.5 \%$, respectively, (a combined increase of $26.84 \%$ ). It should be noted that the annual average income (of the lowest income group) increased by $3.15 \%$ and over the same period of time (i.e. from 2001 to 2006/07) in the Manukau area. This shows that the both water supply and sewerage services charges have increased faster than the annual income increase, since 2001, and the rate of increase of annual income is not proportional to the rate of increase of weekly water and wastewater costs in Manukau. It was observed that slowly the middle income earners were also succumbing towards failing to meet the benchmark (Figure 1).

The results showed that the average water and wastewater charges and the percentage of household income spent on these services increased at a rate of $4.47 \%$ (on average per annum). If they continue to increase at the same rate then the mean weekly water and wastewater charges will increase to $\$ 16.11$; and the lowest earning groups will end up paying just over $5 \%$ of their gross income on water and wastewater service charges by 2012 . This means the lowest income group will be under a continuous financial stress.

\section{General discussion - towards an affordability benchmark}

The way to establish water affordability benchmark is similar to that employed in the context of fuel. A $10 \%$ fuel poverty threshold has been embedded within various government energy policy statements for several years [3]. The details of which can be found in [13]. Sawkins and Dickie [13] reported that there is no commonly agreed affordability benchmark in the UK. For England and Wales an indicative water affordability measure has been adopted by DEFRA (i.e. 3\% of household income). In this study, the threshold for the percentage of disposable income above which water and wastewater charges may represent hardship was taken for illustrative purposes to be $\mathbf{3}$ percent (as mentioned earlier). Dziegielewski et al. [5] reported that selection of a benchmark value is necessarily related to one or more assumptions about its expected value. While several practical methods can be used to decide on which value in the distribution is to be chosen, the simplest approach could be to select a benchmark value that represents a minimum acceptable value based on financial or engineering logic or a median value (which indicates that $50 \%$ of comparable 
peer systems were able to exceed the median value or where appropriate to stay below the median value).

The median of spending by households on water and sewerage charges as a percentage of gross income varies between 2.24 and $2.84 \%$ (an average of $2.54 \%$ - during 2001 and 2006). The percentage ranking showed that the rank of 3\% assumed benchmark value was $57 \%$ in the data set of \%age of gross income spent on water and wastewater charges or in other words, $57 \%$ values were lower than the $3 \%$ value in the data set. Therefore, the choice of $3 \%$ appears to be reasonable as $57 \%$ values were lower than the $3 \%$ in the data set. A $4 \%$ or $5 \%$ values could have been assumed for the study. If that was the case then the lowest to medium income group would have been in a serious financial stress.

Concerning the water affordability benchmark debate, another view point is taken by the Congressional Budget Office (CBO). According to $\mathrm{CBO}$ report on future investment in drinking water and wastewater infrastructure [2], EPA has never adopted a measure to indicate how much an individual household can pay for water services before they become unaffordable. Yet participants in the current debate use (and attribute to EPA) the assumption that any household with water bills in excess of 4 percent of its income is experiencing a hardship. In adopting that notion, they mistakenly apply to individual households "affordability criteria" that the agency developed for whole water systems. The distinction is important because EPA's criteria compare the revenues collected by a water system to the median household income (MHI) in a service area, not to individual household income. Certainly, average household costs that correspond to 4 percent of a community's MHI represent an even higher percentage of the income of an individual household earning less than the median. Thus, EPA's (subjective) judgment that 4 percent of MHI is a reasonable ceiling on a water system's yield does not translate into a judgment that each individual household served by that system should pay no more than 4 percent of its income for water services. The 4 percent benchmark reflects EPA's separate figures of 2 percent each for wastewater and drinking water. The origins of those individual figures highlight the subjectivity inherent in setting affordability criteria. EPA recently decided to raise the value to 2.5 percent of MHI, which highlights the subjective underpinnings of the agency's affordability criterion.

\section{Summary and conclusions}

In this paper we have looked at household income of different income groups and how much each household within each income group is spending on water and wastewater service's charges in the Manukau city. The aim was to analyse and understand better to what extent low income households can afford these services. The last 7 years have seen a marked increase in water and wastewater service's charges. While there were important data limitations (as mentioned earlier in the methodology section), these estimates suggest that affordability is indeed a problem for lowest to median income groups. It is evident that the increasing water and wastewater in Manukau City is putting pressure on the low income earners in the city. The major reason for the increase in water and 
wastewater rates is the vastly increasing population of the city. There are also other reasons such as drinking water standards and environmental legislations which have to be met by suppliers. Based on the findings of this study the following conclusions can be drawn:

- The study showed that since 2001 the average annual water and wastewater charges increased by $7.14 \%$ and $20.5 \%$, respectively.

- The percentage that the lowest income group's income spent on water and wastewater service's charges increased from $3.24 \%$ in 2001 to $4.11 \%$ in 2006 (i.e. an increase of $26.85 \%$ ). The affordability of household water and sewerage service of lowest income group in Manukau City has been over the assumed benchmark since 2001. This showed that lowest income groups have spent a big slice of their income on water and sewerage services than that of highest income group. The percentage that the highest income group's income spent on water and wastewater service's charges increased from $0.54 \%$ in 2001 to $0.68 \%$ in 2006 .

- The average water and wastewater charges and the percentage of household income spent on these services (especially for the lowest income groups) increased at a rate of $4.47 \%$ (on average per annum). If they continue to increase at the same rate then the mean weekly water and wastewater charges will increase to $\$ 16.11$; and the lowest earning groups will end up paying just over $5 \%$ of their gross income on water and wastewater service charges by 2012 , which means the lowest income group will be under a continuous financial stress.

- To the best of our knowledge, there is no information available on an affordability benchmark for household water and sewerage charges for New Zealand. Measuring the affordability of water and wastewater service charges is complex and inexact; household composition and choice are significant factors. For example, as the composition of households varies, so does their ability and desire to spend large proportions of their income on housing costs (including water, wastewater, power, telephone, food, etc). Households with dependent children, for instance, may be less able to spend more of their income on housing costs than households with no dependent children. Furthermore, households with higher incomes are able to exercise more choice over how much they spend on housing costs. No data could be obtained for household composition and an exact amount of water used by each household within each group.

- Affordability can play an important role to analyze the water charge, and check if the water and sewerage service's charges are at a reasonable level. Therefore, introducing the issue "affordability" into the water and wastewater service's charges concepts is necessary, and it may assist the authorities to eliminate or reduce water poor households from the city.

- This study has tried to identify some of the issues, but it has not reduced the need for further, more detailed analysis of the household composition, exact household earning details and water consumption patterns of the lowest to median income households. 


\section{References}

[1] Auckland Water Industry, 2006, Auckland Water Industry Annual Performance Review 2005/06. Available: http://www.aucklandcity .govt.nz/council/documents/awireview/default.asp Accessed: July 2006.

[2] Congressional Budget Office (CBO), 2002, Future investment in drinking water and wastewater infrastructure. Available: http://www.cbo.gov/ ftpdoc.cfm $?$ index $=3983 \&$ type $=08$ sequence $=0$. Viewed on 20 August 2006.

[3] Department for Environment Food and Rural Affairs (DEFRA), 2001, The UK fuel poverty strategy. Department for Environment, Food and Rural Affairs, UK Avalable: http://www.defra.gov.uk/environment/water/industry /review/index.htm Accessed: August 2006.

[4] Department for Environment Food and Rural Affairs (DEFRA), 2004, Principle guidance from the secretary of state to the director general of water services. Periodic Review of Water Price Limits. Department for Environment, Food and Rural Affairs, UK. Available: http://www.defra.gov.uk/environment/water/industry/review/index.htm Accessed: August 2006.

[5] Dziegielewski, B., Beck, R., and Bik, T. 2000. Benchmark investigation of small public water system economics. A project report completed for Midwest Technology Assistance Centre, 2204 Griffith Drive, Champaign, IL 61820-7495, Southern Illinois University, Carbondale, IL 62901-4514.

[6] Fankhauser, S. and Tepic, S. 2006. Can poor consumer pay for energy and water? An affordability analysis for transition countries. Energy Policy, Volume 35(2). Pp. 1038-1049. Elsevier limited.

[7] Fitch, M. 2002. Water poverty in England and Wales - discussion paper. Centre for Utility Consumer Law, University of Leicester.

[8] Herbert, A. and Kempson, E. 1995. Water debt and disconnection. Policy Studies Institute, London.

[9] Huby, M. 1994. Water poverty and social policy: a review of the issues for research. Journal of Social Policy, Vol: 24 (2), pp. 219-236.

[10] Mahmood, B. and Jing, H. (2008). Affordability of household water and sewerage services in Waitakere city - a case study. The $8^{\text {th }}$ Gulf Water Conference on "Water in the GCC. Towards an Optimal Planning and Economic Perspective" held on $3^{\text {rd }}$ March 2006 in Manama, Kingdom of Bahrain.

[11] Manukau Water Limited. 2006. Serving a growing Community Manukau Water Limited is responsible for providing water and wastewater services to the urban areas of Manukau City. [online] Available from http://www.manukauwater.co.nz/ [17 August 2007].

[12] Organization for Economic Cooperation and Development (OECD). 2003. Social Issues in the Provision and Pricing of Water Services. Paris. Available:http://www.oecd.org/dataoecd/12/39/15425332.pdf Accessed: August 2006. 
324 Water Resources Management V

[13] Sawkins, J.W. and Dickie, V.A. (2005). Affordability of household water service in Great Britain. Journal of the Chartered Institution of Water and Environmental Management, Vol. 19 (3), pp. 207-213.

[14] Watervoice. 2004. Watervoice policy statement on water affordability. Watervoice, Birmingham. 